\title{
Do surgical margins matter after mastectomy? A Systematic Review
}

Authors: James Bundred $M B C h B^{(1)}$, Sarah Michael $B S c{ }^{(2,3)}$, Sarah Bowers $B A^{(2,3)}$, Nicola Barnes $M D^{(3)}$, Yasmin Jauhari $M B B S^{(4)}$, Dafydd Plant $M B C h B^{(1)}$, Thomas Maishman $P h D^{(5)}$, Ramsey Cutress $P h D^{(5,6)}$ Bernd Holleczek ${ }^{(7,8)}$, David Dodwell $M D^{(9)}$, Nigel Bundred $M D^{(2,3)}$

\section{Affiliations:}

${ }^{1}$ College of Medical and Dental Sciences, University of Birmingham, Birmingham, UK, B15 2TT

${ }^{2}$ Manchester University NHS Foundation Trust, Wythenshawe, Manchester, UK M23 9LT

${ }^{3}$ University of Manchester, Manchester, UK, M13 9PT

${ }^{4}$ Clinical Effectiveness Unit, Royal College of Surgeons, 35-43 Lincoln's Inn Fields, London, UK, WC2A 3PE

${ }^{5}$ University of Southampton, Tremona Road, Southampton, SO16 6YD, UK

${ }^{6}$ University Hospital Southampton, Tremona Road, Southampton, SO16 6YD, UK.

${ }^{7}$ Division of Clinical Epidemiology and Aging Research, German Cancer Research Center (DKFZ), INF 581, 69120 Heidelberg, Germany

${ }^{8}$ Saarland Cancer Registry, Präsident Baltz-Straße 5, 66119 Saarbrücken, Germany

${ }^{9}$ Nuffield Dept. of Population Health, University of Oxford, UK, OX3 7LF

Correspondence to NJ Bundred. $2^{\text {nd }}$ floor, ERT Building, Manchester University NHS Foundation Trust, Southmoor Road, Manchester, M23 9LT

(Email: Bundredn@manchester.ac.uk; Tel: 0161291 5859)

Declared competing interests of authors:

NJ Bundred received a NIHR Programme Grant investigating margin involvement.

The other authors declare no competing interests.

Key Words: Resection margin, Breast Cancer, Mastectomy

Word count: 2736 


\begin{abstract}
Background

No consensus exists regarding adequacy of margins after mastectomy.

To determine if pathological margin proximity is associated with local (LR) or distant recurrence after mastectomy for early invasive breast cancer or ductal carcinoma in situ.
\end{abstract}

\title{
Methods
}

A systematic review of literature published from 1980-2019 and meta-analysis was conducted. Unpublished data were sought from authors (PROSPERO (CRD42019127541)). Thirty-four studies comprising 34,833 breast cancer patients were included in the quantitative synthesis. Eligible studies reported on patients undergoing curative mastectomy for cancer allowing estimation of outcomes in relation to margin status/width.

The association between pathological margin status and local (LR) and distant recurrence was considered using random effects modelling. PRISMA guidelines were followed.

\section{Results}

Positive margins were associated with increased LR on multivariable analyses (HR, 2.64, $(95 \% \mathrm{Cl} 2 \cdot 01-3 \cdot 46))$ and LR was higher regardless of the distance of tumour from the margin defined as positive. After skin-sparing mastectomy, positive margins were associated with increased LR (HR 3.40, $(95 \% \mathrm{Cl} 1 \cdot 9-6 \cdot 2))$. In the 4 studies reporting distant recurrence, patients with involved margins had a higher risk (HR 1.53, (95\% Cl 1.03-2.25)).

\section{Conclusions}

Failure to achieve clear margins after mastectomy may increase the risks of local and distant recurrence. Adequate margin clearance should be recommended to minimise recurrence after mastectomy in National and International Guidelines. 


\section{Background}

It has been reported that leaving tumour margins involved with cancer leads to an increased risk of local recurrence $(L R)^{(1-4)}$. LR is associated with an increased risk of death from breast cancer ${ }^{(5)}$.

A meta-analysis ${ }^{(2)}$ of 33 studies on breast conserving surgery (BCS) and radiotherapy found margins of $<1 \mathrm{~mm}$ were associated with increased risk of LR (OR: 1.96 (95\% Cl 1.76, 2.24). The relevance of margin status after BCS features prominently in published studies and guidelines but fewer data (and no guidelines) exist describing the association between LR and margin width after mastectomy. After BCS, international guidelines have suggested that leaving tumour margins (invasive cancer or ductal carcinoma in situ (DCIS)) that does not touch the ink at the specimen edge is acceptable because adjuvant radiotherapy will ablate any residual disease ${ }^{(6)}$. Clinicians often apply these guidelines to decisions about mastectomy margins, even though they provide no specific support in this context .

A meta-analysis of 22 studies involving 18,863 women undergoing mastectomy, published in 2010, found an unadjusted relative risk of 2.57 for LR with involved margins, although the data included some patients who had radiotherapy ${ }^{(3)}$. In the absence of radiotherapy, LR was associated with involved or close margins (relative risk 2.60). There were insufficient data on margin status following skin-sparing mastectomy (SSM) techniques ${ }^{(3)}$. These techniques leave breast skin with underlying tissue to preserve skin blood supply enabling longer skin flaps but a greater likelihood of positive margins, which in many circumstances is not followed by radiotherapy ${ }^{(4,7)}$. A previous observational overview of SSM versus simple mastectomy ${ }^{(7)}$ found no difference in LR between these techniques. However, only one of the seven included studies addressed margin status ${ }^{(9)}$ and this found that involved margins predicted local recurrence after SSM.

We performed a systematic review to determine if margin involvement after mastectomy was associated with subsequent local or distant recurrence. 


\section{Methods}

\section{Search strategy and selection criteria}

To determine the evidence for local and distant recurrence risk after SSM and simple mastectomy we reviewed the published literature from Jan 1980 to May 2019.

Articles on patients undergoing mastectomy for breast cancer published between 1980 and May 2019 formed the population for this systematic review. Patients undergoing mastectomy, either simple or skin-sparing formed the population that was studied. Patients with positive versus negative surgical margins, including all distances of tumour from the surgical margin, defined as positive, formed the intervention and comparator groups. Outcomes were LR, distant recurrence and overall survival. PRISMA guidelines were used to design the study and report the findings. The protocol of this systematic review was registered in the Prospective Register of Systematic Reviews (PROSPERO identification code CRD42019127541) ${ }^{(10)}$.

The literature search was conducted using MEDLINE (PubMed), Embase and Proquest online databases, using the search terms 'breast cancer' or 'breast carcinoma' or 'breast neoplasm' or 'Ductal Carcinoma in Situ' (or 'DCIS'), 'mastectomy', and 'resection margin' or 'margin' or 'margins of excision'. The search was limited to articles in English. The bibliographies of relevant studies were examined for further publications.

Studies eligible for inclusion had to meet the following criteria:

1) report on a population of patients undergoing curative mastectomy for (stages I-III) early invasive or in-situ breast cancer

2) allow an estimation of outcomes in relation to margin status;

Patients treated with neoadjuvant chemotherapy or with conservation surgery were excluded; as were reviews and case reports. Conference proceedings were also examined.

\section{Data extraction and outcome definitions}


All eligible studies were identified by two reviewers, who independently extracted data. These data included author name, year of publication, country of study, total number of patients, mean/median age, proportion of male participants, tumour T stage, $\mathrm{N}$ stage and histology, adjuvant treatments, definition of margin positivity, length of follow-up , Hazard Ratios (HRs) and Confidence Intervals(Cis), P values and numbers of patients with LR according to margin status. Any disputes were resolved by a third reviewer. If studies included patients who underwent both BCS and mastectomy, only the mastectomy data were used. Data on molecular subtype were recorded.

\section{Margins}

To standardise synthesis of the evidence on microscopic margins, margin definitions were extracted from papers and reviewed. Where involved margins were described as the presence of (invasive or in-situ) cancer at the transection margin, this was defined as a positive margin and margin distance was considered 0mm. Where involved margins were described as the presence of tumour within a given distance, but not at the resection margin, this was defined as a close margin and the margin distance recorded. Studies reporting margin status as a binary negative versus positive were also included.

\section{Loco-regional recurrence (LRR)}

Definition and data for LRR (either mastectomy chest wall or regional nodal recurrence) were categorised into 'LR' (for studies reporting LR as the first site of relapse, including studies where LR may have occurred alone or simultaneously with regional and/or distant relapse) and 'LR any' (for studies reporting LR at any time or site).

\section{Systemic recurrence}

Data concerning distant recurrence were recorded to allow an estimation of its association with margin proximity and distant disease-free survival to be considered. No data for overall survival were found. 


\section{Methodological Quality}

The studies included in the systematic review provided observational level data, and the analysis was conducted at the study level due to lack of availability of patient level data. Unpublished data were sought from authors.

All studies were graded for methodological and reporting quality using the NewcastleOttawa Scale (NOS) for non-randomised studies ${ }^{(13)}$ (Table 1). This involves scoring the selection of patients into the study, the comparability of the two included cohorts and the assessment of outcomes. Two reviewers scored each paper and disputes were resolved by a third reviewer.

\section{Statistical Analysis}

This systematic review was conducted in accordance with the recommendations of the Cochrane Library and MOOSE guidelines ${ }^{(10-14)}$.

The outcome of interest in this analysis is LR, yet not all patients will experience LR and the timing of LR is relevant. Therefore, this review sought to combine summary estimates from time-to-event data analyses where the most frequently used time-to-event summary statistic of hazard ratios from cox-proportional hazards models were primarily sought and pooled(14). Where available, the adjusted hazard ratios from studies were pooled using random-effects modelling with inverse variance weighting. Unadjusted hazard ratios and binary event data from a given time point, were additionally pooled, and included as supplementary analyses for completeness, and to evaluate consistency with the primary analysis. In studies where patients were stratified into three or greater categories, the results were combined by pooling hazard ratios.

Studies were summarized using forest plots and $\mathrm{I}^{2}$ statistics were calculated as measures of heterogeneity. Adjusted hazard ratios were pooled for studies that reported the impact of positive margins on distant disease-free survival/overall survival. To investigate causes of heterogeneity, the following subgroup analyses were performed: 
1. Invasive cancer only (not including DCIS),

2. DCIS only (without radiotherapy),

3. Lymph node negative patients,

4. Skin-sparing mastectomy only, and

5. Studies published after 2010.

Publication biases were examined using funnel plots and Egger linear regression tests. The Duval and Tweedie trim-and-fill method was used to produce an estimated hazard ratio adjusted for publication biases, where these were found (Table 2).

Statistical analyses were performed using RevMan® version $5 \cdot 3$ (The Cochrane Collaboration, The Nordic Cochrane Centre, Copenhagen, Denmark) and R Statistical Software (R version 3·5.2).

\section{Results}

\section{Study Characteristics}

Overall, 2,199 papers were screened and 34 studies (34,833 patients, median patient age 55 years) were included (Figure 1). Studies identified were from North America $(n=19)$, Australasia ( $n=6)$ and Europe $(n=9)$. Studies had a median follow-up period of 70 months, with a range of 41 months to 164 months.

Reporting standards and methodological quality

Median Newcastle-Ottawa score ${ }^{(13)}$ for all studies was 7 (interquartile range 6-7-25) with only one study scoring below 5 , indicating generally high-quality cohort studies (Table 1).

Criteria for defining positive margins varied considerably across the included studies. Of the 34 studies, 6 presented adjusted hazard ratios from multivariable models only, 1 presented an unadjusted hazard ratio from a univariable only, 3 presented both and 11 presented both univariable and multivariable derived hazard ratios, as well as adequate data to calculate odds ratios. Additionally, 9 studies presented data that only allowed calculation of odds 
ratios. 4 studies did not present sufficient data to calculate summary statistics, presenting only total numbers of recurrence.

Eleven studies described positive margins as tumour at ink , 5 as tumour $<1 \mathrm{~mm}, 11$ as tumour $<2 \mathrm{~mm}$, 2 as tumour $<3 \mathrm{~mm}$, one as tumour $<4 \mathrm{~mm}, 1$ as tumour $<5 \mathrm{~mm}$ and one as tumour $<10 \mathrm{~mm}$ (all compared to a wider margin, with two studies not specifying the margin distance considered positive. 4 studies additionally reported hazard ratios for distant disease-free recurrence.

Positive Margin Incidence

Among 22598 patients in Across-34 included studies 2,871 (12.7\%) had positive or close margins___Studies reported from North America,_found 1600 of 14,522 patients (11.0\%) had positive or close margins whereas, 171 of 776 patients (22.0\%) had positive or close

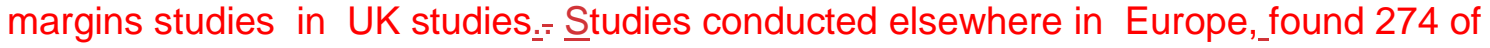
2258 patients (12.1\%) had positive or close margins whereas studies reported from Asia and Australasia, 826 of 5042 patients (16.4\%) had positive or close margins.

\section{Locoregional Recurrence}

Of_32,145 patients with binary local recurrence data , 1768 patients developed local recurrence (5.5\%). The results from the 34 studies included in the systematic review are summarised in table 2.

The association between margin status and LR was reported in 7 studies $(4,15,20,28,36,39,44)$. In the univariable analyses, positive or close margins were associated with increased LR (HR $2 \cdot 88(95 \% \mathrm{Cl} 2 \cdot 06,4 \cdot 03))$ (Supplementary Figure 1). Studies were grouped by their description of a positive margin, with all descriptions of a positive margin associated with increased LR (tumour at ink: HR $2 \cdot 77(95 \% \mathrm{Cl} 1 \cdot 70,4 \cdot 54),<1 \mathrm{~mm}: 3 \cdot 15$ (95\% Cl 1·70, 5.82), <2mm: $2 \cdot 78(95 \% \mathrm{Cl} 1 \cdot 41,5 \cdot 49))$. Heterogeneity was low amongst studies $\left(\mathrm{I}^{2}=0 \%\right)$. 
19 studies reported the adjusted impact of positive or close resection margins on LR from multivariable models ${ }^{(4,9,15,17,20-22,26,28-29,34,35,37-39,43-48)}$ (Figure 2). Positive or close margins were associated with increased LR, HR 2.64 (95\% Cl 2.01, 3.46). Factors considered in multivariable analyses included molecular subtype ${ }^{(4,20-22.26-28,37,39,48)}, \operatorname{stage}^{(4,20-22,26-28,37,39,48)}$ and use of adjuvant therapy (radiotherapy and chemotherapy) (Table 1). Heterogeneity of studies was moderate at $65 \cdot 9 \%$. Positive margins were consistently associated with increased LR, regardless of the study description of a positive margin: tumour at ink: HR $2 \cdot 29(95 \% \mathrm{Cl} 1.35,3.89)$ and margins of <1mm: $3.08(95 \% \mathrm{Cl} 1.60,5.93),<2 \mathrm{~mm}: 2.96$ (95\% Cl 2.20, 3.98), <3mm 2.57 (95\% Cl 0.90, 7.32) and <5mm: 7.09 (95\% Cl 1.32, 1.38).

\section{Subgroup Analysis}

The results of all subgroup analyses are presented in table 2.

5 studies reported hazard ratios for patients with clinical stage T1-3, N0 or for whom no lymph nodes were found to contain tumour following surgery ${ }^{(4,21,22,41,45)}$. The pooled hazard ratio for involved margins and LR was HR $3.06\left(95 \% \mathrm{Cl} 2 \cdot 15,4 \cdot 37, \mathrm{p}<0 \cdot 001, \mathrm{I}^{2}=0 \%\right)$ (Supplementary Figure 2A).

5 studies considered the association between positive margins on LR in patients with DCIS only $(29,36,38,43,44)$, with a pooled HR of $2.91(95 \% \mathrm{Cl} 1.94,4.36)$ (Supplementary Figure 2B). Heterogeneity was low between studies $\left(I^{2}=0 \%\right)$. Egger regression testing did not suggest any significant publication bias.

In 4 studies investigating LR after SSM, involved margins predicted LR (HR $3.40(95 \% \mathrm{Cl}$ $1 \cdot 90,6 \cdot 20)^{(4,9,15,16)}$ (Figure 3).

4 studies ${ }^{(4,8,17,37)}$ reported the association between positive margins and distant disease-free survival (DDFS) in a multivariate analyses. Positive margins (defined as $<1 \mathrm{~mm}$ ) were associated with worse DDFS outcomes (HR 1.53 (95\% Cl 1.03, 2.25, p=0.03)). There was marked heterogeneity of included studies $I^{2}=84 \%$ (Figure 4). 


\section{Absolute Difference in local recurrence with Positive Margins}

Across all 15 studies reporting absolute numbers of positive margins and local recurrence as a binary outcome (Supplementary Figure 3), 103 of 905_(11.3\%) patients developed LR with positive margins compared to $391(4.6 \%)$.- of 8434 patients with negative margins . Odds ratios (OR) calculated from this data indicate positive or close resection margins were associated with an increased risk of LR (OR $2 \cdot 75,(95 \%$ CI 1.94, 3.88)). The OR of LR with positive margins increased with follow-up time of $\geq 5$ years compared to $<5$ years (OR<5years: $2 \cdot 15(95 \% \mathrm{Cl} 1 \cdot 14,3 \cdot 27)$ to $\mathrm{OR}>5$ years $3.50(95 \% \mathrm{Cl} 2 \cdot 13,5 \cdot 75))$. (Supplementary Figure 4)

Invasive cancer only subgroup

12 studies reported data for patients with invasive cancer only. In this subgroup, positive margins were associated an increased risk of LR (HR 2.44, (95\% Cl 1.78, 3.34, p<0.001, $\mathrm{I}^{2}$ $=58 \%)$ ). Data were available from 7 studies of patients not receiving radiotherapy $(15,21,22,26,35,45,46,47)$. In this subgroup, positive margins were associated with an increased risk of LR (HR 3.52, (95\% Cl 2.56, 4.84)).

Fourteen studies published since 2010 , reported multivariable hazard ratios for the impact of margin involvement on LR and found positive margins to be associated with an increased risk of LR (HR $\left.2.83\left(95 \% \mathrm{Cl} 2.05,3.90, \mathrm{p}<0.001, \mathrm{I}^{2}=49 \%\right)\right)$.

\section{Discussion}

This systematic review has demonstrated a clear consistent association between involved pathological margins and LR after mastectomy. Specifically, a patient with a positive or close margin after mastectomy is associated with a two to threefold increased risk of LR in comparison to a patient with negative margins. This strong association between margin proximity and LR was demonstrated irrespective of the use of radiotherapy or an individual study's description of 'involved margins'. 


\section{Strengths and Weaknesses}

This the large study, includes over 34,000 women, more than double the number of patients included in the 2009 meta-analysis addressing this issue ${ }^{(3)}$. Our analysis utilised combined hazard ratios which is the accepted standard for reporting time-to-event data, whereas the previous meta-analysis used binary outcome data, which introduces bias due to the varying follow up lengths of included studies. We also sought to minimize the risk of publication bias and reported study quality using standard criteria.

Publication level data was used as individual patient-level data were unavailable which limits the ability to explore the association of many variables with outcomes. Additionally, as with any observational study there is always the possibility that unseen confounders may influence the associations identified. The site of margin proximity was not defined and the definition of a positive margin varied throughout the studies included, although the majority used $<1$ or $<2 \mathrm{~mm}$ as a cut-off point. Only 4 studies reported the association between margin involvement and distant recurrence and few studies reported solely on skin sparing mastectomy, although within the meta-analysis, minimal calculated heterogeneity between included studies was found.

Other studies

A national quality assurance initiative conducted in Holland from 2003 to 2008, mandated all Dutch breast surgeons achieve less than $10 \%$ cases with margin involvement. Across 23,121 patients, there was an observed reduction rate of margin involvement and LR (to $2 \cdot 4 \%$ LR by 2008$)^{(18,19)}$. This audit resulted in reduced distant metastasis, lower costs for additional chemotherapy and surgery and improved cancer survival ${ }^{(18,19)}$. A UK study of 3,204 patients found that $19 \%$ of patients had involved margins ( $9 \%$ had ink on tumour cells and $10 \%$ had margins $<1 \mathrm{~mm}$ ), which was associated with increased distant recurrence and poorer overall survival ${ }^{(17)}$. 
Margin involvement $(<1 \mathrm{~mm})$ after mastectomy in one UK unit ranged from $15 \%$ after simple mastectomy to $29 \%$ after SSM and these were independently associated with LR (HR 3.3 $(95 \% \mathrm{Cl} 1 \cdot 6,6 \cdot 8))^{(4)}$. The LR rate at 5 years of $5.6 \%$ increased to $9 \%$ by 8 years in the SSM and reconstruction group ${ }^{(4)}$.

A meta-analysis of SSM versus simple mastectomy reported no difference in LR from 7 studies ${ }^{(7)}$ but only one study examined margin status ${ }^{(9)}$. LR after SSM with positive margins was threefold higher (HR 3.4) and increased with longer follow-up time ( $\geq 5$ years compared to $<5$ years). LR therefore appeared to be associated with margin involvement but not the operation performed.

Implications

The Early Breast Cancer Trialists' Collaborative Group (EBCTCG) meta-analysis of locoregional radiotherapy provides robust evidence that locoregional recurrence is causally detrimental to long-term breast cancer survival and that the prevention of four LRs prevents one breast cancer death ${ }^{(5)}$. In support of this, our systematic review demonstrated an association between distant recurrence and margin involvement of borderline significance, but more studies are needed to examine this association further.

Pathological margins were not reported in the EBCTCG meta-analysis and this reflects the inability to address oncological outcomes according to margin status with prospective randomised evidence. Moreover, since clinical trials usually stipulate clear margins for patient inclusion, the only published data on pathological margins is from cohort or retrospective studies. Margin proximity cannot be directly assessed in randomised trials.

The American Society of Clinical Oncology (ASCO) and the American Society of Radiation Oncology (ASTRO) guidelines relating to invasive cancer indicate that "a positive margin is defined as the presence of ink at the surface of the surgical specimen on either invasive tumour cells or DCIS" and any wider margin is an acceptable margin clearance after surgery, but most of the evidence on margin width relates to BCS followed by radiotherapy ${ }^{(6)}$. In 
contrast the ASCO / Society of Surgical Oncology (SSO) DCIS Guidelines state a 2mm margin of clearance is required because "gaps of uninvolved tissue occur between foci of DCIS"(49,50). The clear discordance between these guidelines adds to confusion as many invasive cancers exhibit surrounding DCIS.

A wider margin than "tumour on ink" is required. The meta-analysis for invasive cancer in the ASCO guidelines used a $1 \mathrm{~mm}$ margin (not ink on tumour) as its referent control( ${ }^{(2,6)}$ because of the small number of cases with "tumour on ink". In contrast, the DCIS meta-analysis ${ }^{(49,50)}$ used both a binary referent model combining "ink on tumour" and $<1 \mathrm{~mm}$ margin categories versus all other margin widths, while a network meta-analysis ${ }^{(49)}$ which included more than one margin width per study in their analysis and produced a different result with an OR of 0.5 for margins $>2 \mathrm{~mm}(\mathrm{p}<0.001)$ in reducing the risk of LR. A recent UK population-based observational study of 24,770 women with unilateral screen-detected DCIS also reported a progressive and similar reduction in recurrence with greater margin widths following BCS with or without radiotherapy or mastectomy. This association was statistically significant across the whole patient cohort but there was only a weak association in the smaller subgroup analysis of local treatments ${ }^{(51)}$.

Extrapolating these DCIS guidelines to invasive cancer would require a margin clearance of

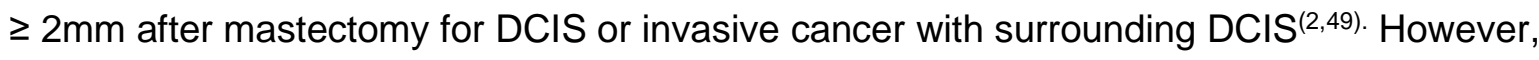
the invasive cancer ASCO guidelines are not relevant in instances where adjuvant radiotherapy is not standard practice after mastectomy (i.e. the majority of patients with node negative invasive cancer or DCIS) despite involved invasive margins.

The results of our study have specific implications for patients undergoing reconstructive surgery with SSM, where large amounts of skin remains in-situ and the primary incision(usually sited around the areola ) to remove the breast is remote from the tumour site. Patients in this scenario might have any margin width accepted and may not routinely be offered radiotherapy or further excision of involved or close margins, to prevent cosmetic deterioration. ${ }^{(51)}$. Therefore, patients receiving SSM would benefit from better preoperative 
planning of mastectomy incisions prior to reconstructive surgery and greater skin excision near the cancer.Postmastectomy radiotherapy did not reduce the HR for LR in this metaanalysis . Guidelines ${ }^{(6,52)}$ also do not recommend post-mastectomy radiotherapy for DCIS or for node negative patients, thus it is crucial a clear margin of $2 \mathrm{~mm}$ around the tumour is obtained.

More than 25 years after demonstrating that LR increases with smaller margin widths or involved margins, there remains no consensus on what constitutes a negative margin after mastectomy and variability in opinion and practice ${ }^{(6.52) .}$ Guidelines, applicable to BCS are an undue influence on considerations of margin adequacy after mastectomy. This systematic review has shown a consistent 2-3.5 fold higher risk of LR associated with margin proximity. If this association is causal, then an adequate surgical margin clearance of $>1 \mathrm{~mm}$ after mastectomy should be recommended in International Guidelines to minimize local and distant recurrence. Quality assurance of Breast Surgery Units should include pathological margin clearance after both BCS and mastectomy and LR rates. 


\section{Figure and Table Legends (Non Supplementary)}

Figure 1. PRISMA Diagram depicting the flow of citations through systematic database searching to record data selection and inclusion in the systematic review

Figure 2. Forest plot of Time-to-LR - multivariate analysis of involved margin width and Local Recurrence after mastectomy in Breast Cancer (Margin width assessed at Tumour at ink, less than $1 \mathrm{~mm}, 2 \mathrm{~mm}, 3 \mathrm{~mm}$ or $5 \mathrm{~mm}$ )

Figure 3. Forest Plot of pooled hazard ratios for local recurrence in patients undergoing Skinsparing Mastectomy with involved margins versus uninvolved

Figure 4. Forest plot of pooled hazard ratios for Distant Disease-free Survival from Breast Cancer for patients undergoing mastectomy with involved versus uninvolved margins.

Table 1. Summary of characteristics of studies in the systematic review and effects of surgical margins on local recurrence in invasive cancer.

Table 2. Summary of results, including all subgroups. $I^{2}$ denotes heterogeneity, Egger regressions are a measure of publication bias and corrected HRs are produced from duval and tweedie trim and fill methods. 
Figure 1. PRISMA Diagram depicting the flow of citations through systematic database

\section{searching to record selection and inclusion of studies}

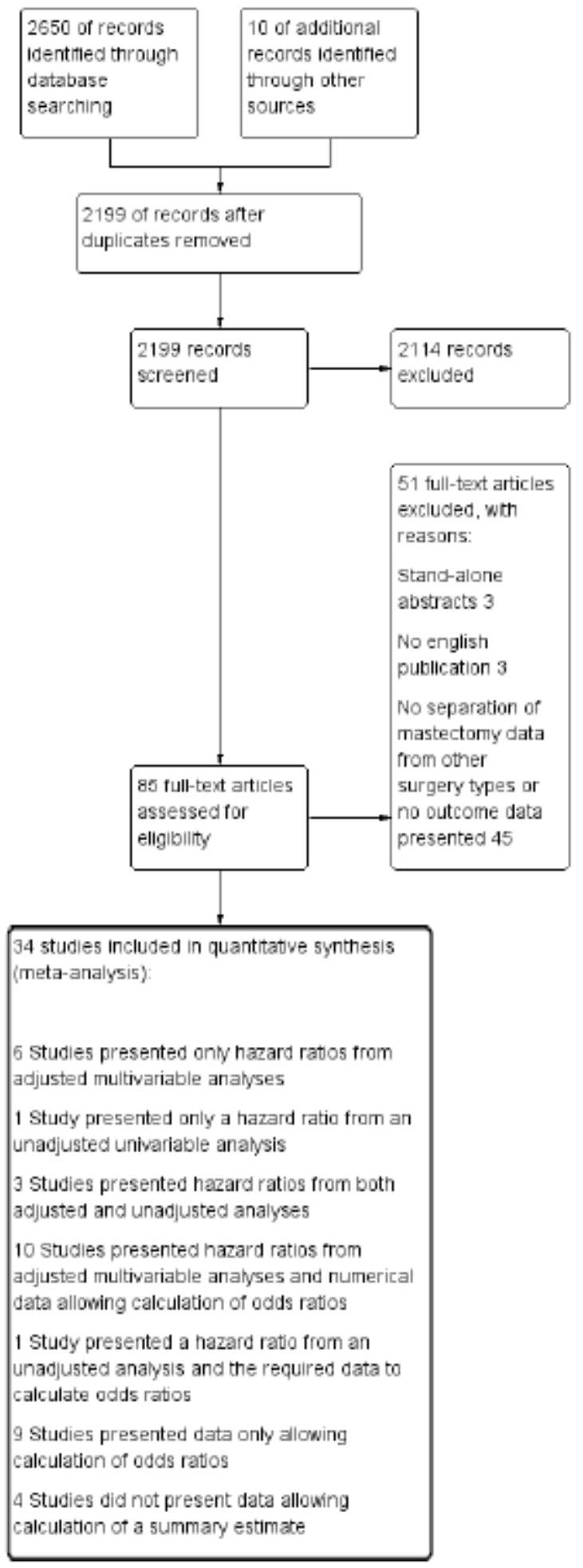


Figure 2. Time-to-LR (Hazard Ratio)- multivariate analysis of involved margin width and

Local Recurrence after mastectomy in Breast Cancer (Margin width assessed at Tumour at ink, less than $1 \mathrm{~mm}, 2 \mathrm{~mm}, 3 \mathrm{~mm}$ or $5 \mathrm{~mm}$ )

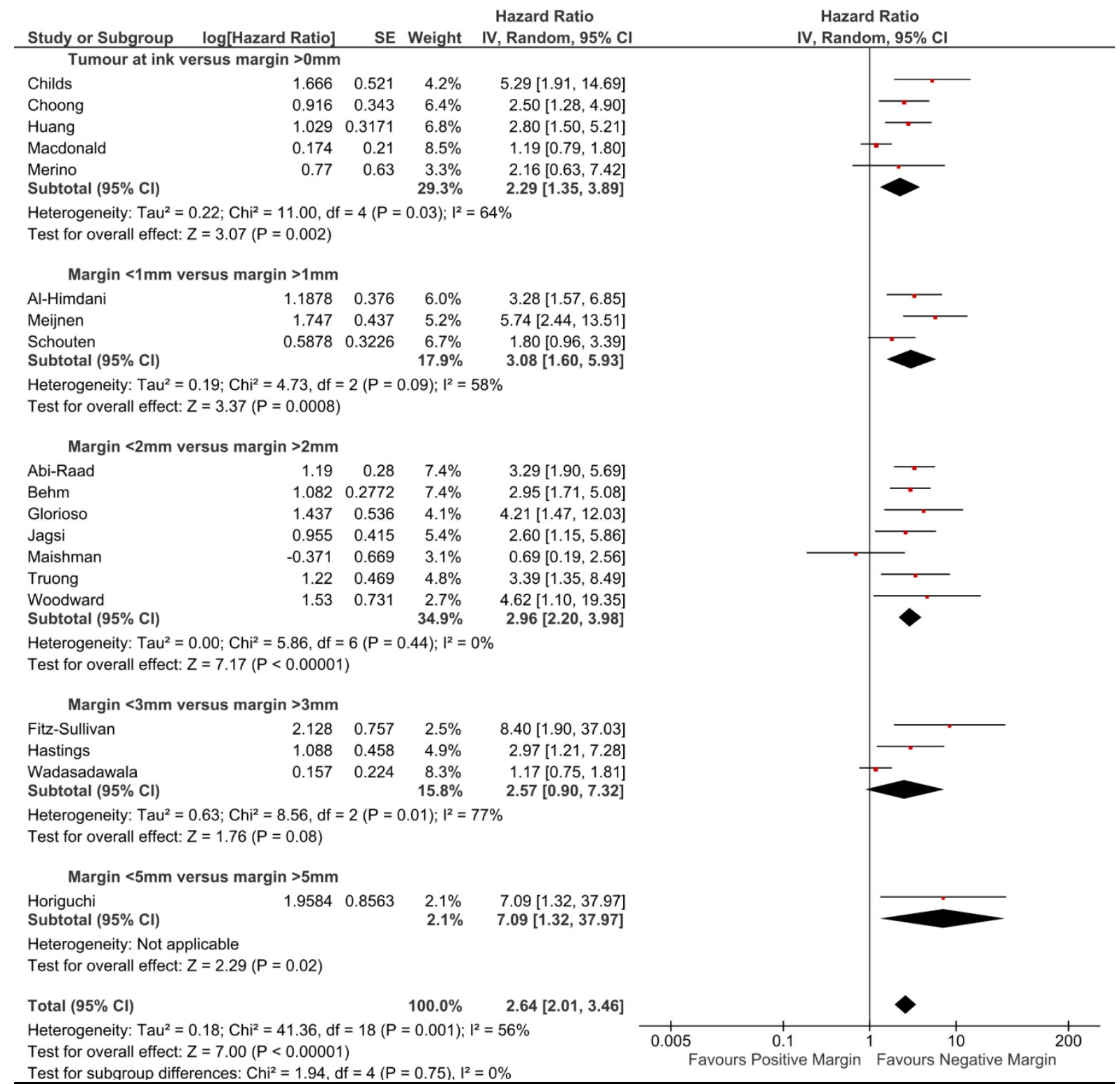


Figure 3. Hazard Ratios for margin involvement and Local Recurrence in patients undergoing Immediate Breast Reconstruction with a Skin-sparing Mastectomy

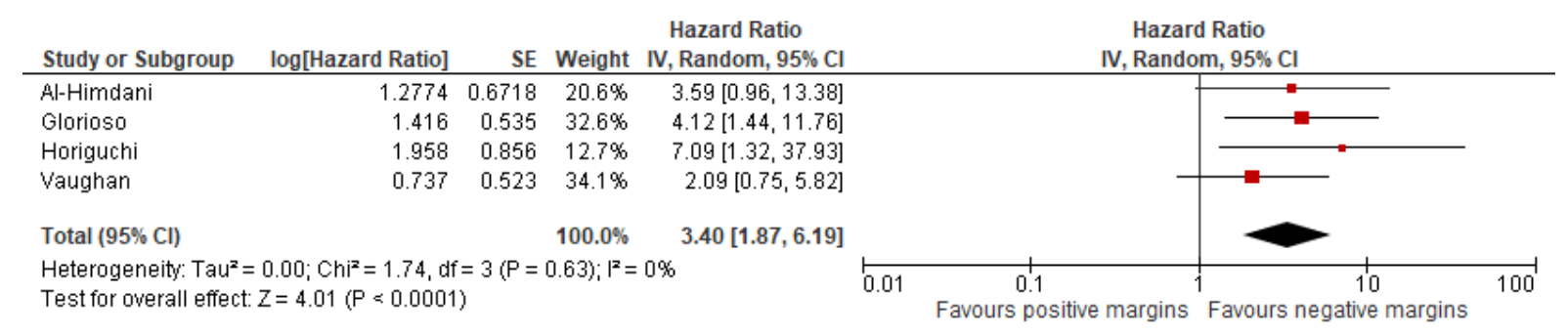


Figure 4. Forest plot of pooled hazard ratios for time to Distant Disease-free Survival from

Breast Cancer for patients undergoing mastectomy with involved versus uninvolved margins.

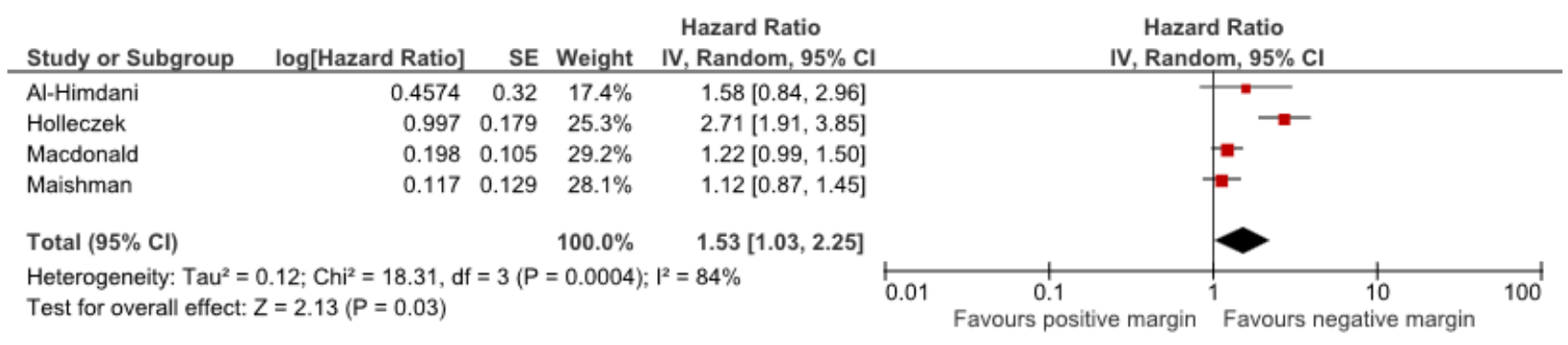




\begin{tabular}{|c|c|c|c|c|c|c|c|c|c|c|c|c|c|c|c|c|c|c|c|}
\hline & $\begin{array}{l}\text { Cancer } \\
\text { type }\end{array}$ & Country & $\begin{array}{l}\text { Years } \\
\text { studied }\end{array}$ & $\begin{array}{l}\text { Median } \\
\text { Follow-up } \\
\text { (months) }\end{array}$ & $\begin{array}{l}\mathrm{P} \\
\mathrm{C} \\
\mathrm{R}\end{array}$ & $\begin{array}{c}\mathrm{T} \\
\text { stage }\end{array}$ & $\begin{array}{l}\mathrm{N} \\
\text { stage }\end{array}$ & $\begin{array}{l}\text { Numbe } \\
\text { r of } \\
\text { patients }\end{array}$ & $\begin{array}{l}\text { Number } \\
\text { Lymph } \\
\text { node } \\
\text { positive }\end{array}$ & $\begin{array}{c}\text { Number } \\
\text { receiving } \\
\mathrm{RT}^{\star \star}\end{array}$ & $\begin{array}{l}\text { Number } \\
\text { receiving } \\
\mathrm{CT}^{\star \star \star}\end{array}$ & $\begin{array}{l}\text { Molecular } \\
\text { phenotyp } \\
\text { e }\end{array}$ & $\begin{array}{c}\text { Margin } \\
(\mathrm{mm}) \\
\text { Definition }\end{array}$ & $\begin{array}{c}\text { Total } \\
\text { patients }\end{array}$ & $\begin{array}{l}\text { Median } \\
\text { Age }\end{array}$ & $\begin{array}{c}\text { Margins } \\
\text { Involved } \\
\mathrm{N}(\%)\end{array}$ & $\begin{array}{c}\text { Close to } \\
\text { margins } \\
\mathrm{N}(\%)\end{array}$ & $\begin{array}{l}\text { Margins not } \\
\text { involved or } \\
\text { close } \mathrm{N}(\%)\end{array}$ & $\begin{array}{c}\text { Overall LR } \\
\text { relapse } \\
\mathrm{N}(\%)\end{array}$ \\
\hline Abi-Raad 2011 & IC & USA & $\begin{array}{l}1980- \\
2004\end{array}$ & 108 & $\mathrm{RC}$ & T1-2 & NO & 1,136 & 0 & 0 & 166 & ER & 2 & 1,136 & 62 & $60(5 \%)$ & $10(1 \%)$ & $1021(94 \%)$ & $60(5 \%)$ \\
\hline Ahlborn 1988 & IC & USA & $\begin{array}{l}1875- \\
1980\end{array}$ & 47 & $\mathrm{R}$ & T1-2 & NO & 322 & 0 & 0 & 0 & NS & 4 & 346 & NS & NS & $90(27 \%)$ & $256(73 \%)$ & $12(4 \%)$ \\
\hline Al-Himdani 2016 & IC & UK & $\begin{array}{l}2000- \\
2005 \\
\end{array}$ & 80 & $\mathrm{RC}$ & T1-3 & $\mathrm{NO}-2$ & 577 & 217 & 141 & NS & NS & 1 & 577 & 62 & 101(17\%) & $12(3 \%)$ & $464(80 \%)$ & $36(6.3 \%)$ \\
\hline Behm 2013 & $\begin{array}{l}\text { DCIS, } \\
\text { IC }\end{array}$ & AUS & $\begin{array}{l}1997- \\
2007\end{array}$ & 95 & $\mathrm{RC}$ & Tis-3 & N0-pos & 2,300 & 837 & 1457 & 1112 & ER, PR & 2 & 2,300 & 57 & $43(2 \%)$ & NS & $2257(98 \%)$ & $88(3.8 \%)$ \\
\hline Cataliotti 1992 & DCIS & Italy & $\begin{array}{l}1968- \\
1990 \\
\end{array}$ & 94 & $\mathrm{R}$ & Tis & NS & 192 & NS & 34 & 0 & NS & NS & 103 & 54 & NS & NS & NS & $11(3 \%)$ \\
\hline Childs 2012 & DCIS & USA & $\begin{array}{l}1998- \\
2005\end{array}$ & 91 & $\mathrm{R}$ & Tis & NO & 145 & 0 & 3 & 90 & $\begin{array}{l}\text { ER, PR, } \\
\text { HER2 }\end{array}$ & 2 & 145 & 52 & $21(14 \%)$ & $23(16 \%)$ & 101(70\%) & $2(1 \%)$ \\
\hline Childs 2012 (1) & IC & USA & $\begin{array}{l}1998- \\
2005 \\
\end{array}$ & 80 & $\mathrm{R}$ & T1-3 & $\begin{array}{c}\mathrm{N} 0- \\
\mathrm{N} 2+ \\
\end{array}$ & 397 & 68 & 0 & 151 & $\begin{array}{l}\text { ER, PR, } \\
\text { HER2 }\end{array}$ & 0 & 397 & 55 & $54(14 \%)$ & $68(17 \%)$ & $275(69 \%)$ & $14(3.5 \%)$ \\
\hline Choong 2010 & IC & Malaysia & $\begin{array}{l}1998- \\
2002\end{array}$ & 57 & $\mathrm{RC}$ & T1-3 & NO-N2+ & 522 & 276 & 345 & 386 & ER & 0 & 522 & 50 & $77(15 \%)$ & $91(17 \%)$ & $354(68 \%)$ & $86(16.4 \%)$ \\
\hline $\begin{array}{l}\text { Fitz-Sullivan } \\
2013\end{array}$ & DCIS & USA & $\begin{array}{l}1996- \\
2009\end{array}$ & 75.6 & $\mathrm{R}$ & Tis & NO & 810 & 0 & 7 & 0 & ER & 1 & 810 & 52 & $5(0.6 \%)$ & $54(7 \%)$ & 751(93\%) & $8(1 \%)$ \\
\hline Freedman 1998 & NS & USA & $\begin{array}{l}1985- \\
1994\end{array}$ & 60 & $\mathrm{R}$ & T1-3 & N1-3 & 789 & NS & NS & 23 & NS & 5 & 789 & 43 & NS & $22(3 \%)$ & 767(97\%) & $5(0.6 \%)$ \\
\hline Gentilini 2006 & IC & Italy & $\begin{array}{l}1995- \\
2002 \\
\end{array}$ & 41 & $\mathrm{R}$ & T2-3 & NO-1 & 195 & 46 & 195 & 195 & NS & 0 & 195 & NS & $24(12 \%)$ & NS & 171(88\%) & $13(4 \%)$ \\
\hline Glorioso 2017 & $\begin{array}{c}\text { DCIS, } \\
\text { IC }\end{array}$ & USA & $\begin{array}{l}2006- \\
2010\end{array}$ & 57 & $\mathrm{R}$ & Tis-3 & $\mathrm{NO}-\mathrm{N}+$ & 1,147 & 518 & 0 & 700 & NS & 2 & 1,147 & 59 & $68(6 \%)$ & $90(8 \%)$ & $1048(91 \%)$ & $58(5 \%)$ \\
\hline Goulart 2010 & IDC & Canada & $\begin{array}{l}1989- \\
2000\end{array}$ & 120 & $\mathrm{R}$ & T3 & No & 100 & 0 & 44 & 48 & NS & 0 & 100 & NS & $9(9 \%)$ & $5(5 \%)$ & $86(86 \%)$ & $9(3 \%)$ \\
\hline Hastings 2014 & $\begin{array}{l}\text { IDC, } \\
\text { ILC }\end{array}$ & USA & $\begin{array}{l}1994- \\
2004\end{array}$ & 98 & $\mathrm{R}$ & T1 & NO & 1,259 & 0 & 0 & 305 & $\begin{array}{c}\text { ER, } \\
\text { HER2 }\end{array}$ & 3 & 1,259 & 64.5 & $107(8 \%)$ & NS & 1152(92\%) & $33(3.2 \%)$ \\
\hline Hehr 2004 & NS & Germany & $\begin{array}{l}1989- \\
2000\end{array}$ & NS & & T3-4 & NS & 287 & NS & 287 & 77 & NS & 10 & 287 & 61 & NS & NS & NS & NS \\
\hline Holleczek 2019 & IC & Germany & $\begin{array}{l}1999- \\
2009\end{array}$ & 120 & $\mathrm{RC}$ & T1-4 & NO-N+ & 1896 & NS & NS & NS & $\begin{array}{c}\text { ER- } \\
\text { HER2+ }\end{array}$ & 1 & 2,290 & 63 & NS & NS & NS & NS \\
\hline Horiguchi 2006 & IC & Japan & $\begin{array}{l}1980- \\
2001 \\
\end{array}$ & 69 & $\mathrm{RC}$ & NS & NS & 1,574 & NS & NS & NS & NS & 5 & 1,574 & NS & $60(4 \%)$ & NS & $1,514(96 \%)$ & $60(19 \%)$ \\
\hline Huang 2004 & NS & USA & $\begin{array}{l}1974- \\
2000\end{array}$ & 70 & $\mathrm{R}$ & T1-4 & $\mathrm{NO}-3$ & 542 & NS & 542 & 542 & NS & 0 & 542 & 50 & $19(4 \%)$ & $41(8 \%)$ & $477(88 \%)$ & $54(17 \%)$ \\
\hline Jagsi 2004 & IC & USA & $\begin{array}{l}1980- \\
2000\end{array}$ & 100 & $\mathrm{RC}$ & T1-3 & $\mathrm{NO}-1$ & 877 & NS & NS & 74 & NS & 2 & 877 & 64 & $19(2 \%)$ & $45(5 \%)$ & 813(93\%) & $46(5.2 \%)$ \\
\hline Klein 2015 & DCIS & Canada & $\begin{array}{l}1994- \\
2003\end{array}$ & NS & $\mathrm{R}$ & Tis & NS & 1,546 & NS & NS & NS & NS & 2 & 1,546 & 57 & NS & $668(43 \%)$ & 956(57\%) & $36(2.3 \%)$ \\
\hline Macdonald 2005 & IC & Canada & $\begin{array}{l}1989- \\
1998\end{array}$ & 101 & $\mathrm{R}$ & T1-4 & N1-3 & 4,181 & NS & 939 & 1120 & NS & 0 & 4,181 & NS & $226(5 \%)$ & NS & $3,955(95 \%)$ & $349(8.3 \%)$ \\
\hline Maishman 2017 & $\begin{array}{l}\text { IDC, } \\
\text { ILC }\end{array}$ & UK & $\begin{array}{l}2000- \\
2008 \\
\end{array}$ & 87 & PC & NS & $\mathrm{NO}-3$ & 1,464 & 910 & 1006 & 1364 & $\begin{array}{l}\text { ER, PR, } \\
\text { HER2 }\end{array}$ & 2 & 1,464 & 36 & $98(8.9 \%)$ & $97(8.8 \%)$ & 910(82\%) & $29(2.6 \%)$ \\
\hline Meijnen 2008 & DCIS & Holland & $\begin{array}{l}1986- \\
2005\end{array}$ & 80 & $\mathrm{R}$ & Tis & No & 504 & 0 & 119 & 0 & NS & 1 & 504 & 51 & $32(6 \%)$ & $48(10 \%)$ & $424(84 \%)$ & $27(5.3 \%)$ \\
\hline
\end{tabular}




\begin{tabular}{|c|c|c|c|c|c|c|c|c|c|c|c|c|c|c|c|c|c|c|c|}
\hline Merino 2018 & IC & Chile & $\begin{array}{l}1997- \\
2006 \\
\end{array}$ & 61 & $\mathrm{R}$ & \begin{tabular}{c|c|} 
T1-3 \\
\end{tabular} & NS & 2,201 & NS & 1375 & 897 & HER2 & 0 & 2,201 & 55 & $90(4 \%)$ & NS & 671(30\%) & $132(41 \%)$ \\
\hline Rashtian 2008 & DCIS & USA & $\begin{array}{l}1994- \\
2002 \\
\end{array}$ & 61 & $\mathrm{R}$ & Tis & NS & 574 & 0 & 0 & 0 & NS & 2 & 574 & 65 & $31(5 \%)$ & $49(9 \%)$ & 494(86\%) & $6(7.5 \%)$ \\
\hline $\begin{array}{c}\text { Rauschecker } \\
1998 \\
\end{array}$ & IC & Germany & $\begin{array}{l}1983- \\
1989 \\
\end{array}$ & 96 & $R$ & T1 & NO & 1,036 & 0 & 1036 & 0 & NS & 2 & 1,036 & NS & NS & NS & NS & 91(28\%) \\
\hline Sakamoto 2016 & IC & Japan & $\begin{array}{l}2003- \\
2011 \\
\end{array}$ & 61 & $\mathrm{R}$ & NS & $\mathrm{NO}-\mathrm{N}+$ & 421 & 88 & 54 & 181 & $\begin{array}{l}\text { ER, } \\
\text { HER2 }\end{array}$ & 2 & 421 & NS & NS & $38(9 \%)$ & 383(91\%) & $11(2.6 \%)$ \\
\hline Schouten 2007 & NS & Netherlands & NS & 59 & $\mathrm{R}$ & \begin{tabular}{c|c|}
$T 1-3$ \\
\end{tabular} & NS & 798 & NS & 153 & 8 & NS & 1 & 798 & 58 & $33(4 \%)$ & $48(6 \%)$ & $718(90 \%)$ & $83(10.4 \%)$ \\
\hline Timbrell 2017 & DCIS & UK & $\begin{array}{l}2000- \\
2010 \\
\end{array}$ & 65 & $\mathrm{RC}$ & Tis & NS & 199 & NS & 7 & 7 & NS & 2 & 199 & 53 & NS & $57(29 \%)$ & $141(71 \%)$ & $8(4 \%)$ \\
\hline Truong 2004 & IC & Canada & $\begin{array}{l}1989- \\
1998\end{array}$ & 93 & $\mathrm{R}$ & $\begin{array}{c}\text { T1-2 } \\
\end{array}$ & No & 2,570 & NS & 41 & 24 & NS & 2 & 2,570 & 56 & NS & $94(4 \%)$ & $2476(96 \%)$ & $10(0.4 \%)$ \\
\hline Truong 2013 & IC & USA & $\begin{array}{l}2003- \\
2009\end{array}$ & 51.6 & $\mathrm{R}$ & T1-2 & NO & 1,994 & 0 & 0 & 644 & NS & 2 & 1,994 & 59 & NS & $142(7 \%)$ & 1852(93\%) & $42(2.1 \%)$ \\
\hline Vaughan 2007 & NS & USA & $\begin{array}{l}1999- \\
2006 \\
\end{array}$ & 59 & $\mathrm{R}$ & \begin{tabular}{c|} 
Tis- 4 \\
\end{tabular} & $\mathrm{NO}-\mathrm{N}+$ & 206 & 57 & 42 & NS & NS & 1 & 206 & 42 & NS & $29(14 \%)$ & $177(86 \%)$ & $11(3 \%)$ \\
\hline $\begin{array}{c}\text { Wadasadawala } \\
2017 \\
\end{array}$ & IC & India & $\begin{array}{l}2005- \\
2011 \\
\end{array}$ & 59 & $\mathrm{R}$ & $\begin{array}{l}\text { T1- } \\
\text { T2 } \\
\end{array}$ & N1 & 242 & 242 & 0 & 242 & NS & 3 & 242 & 55 & NS & $210(86.8 \%)$ & $32(13 \%)$ & $10(3 \%)$ \\
\hline Woodward 2003 & NS & USA & $\begin{array}{l}1975- \\
1994\end{array}$ & 164 & $\mathrm{R}$ & T1-2 & N1 & 1,501 & 1331 & 470 & 1401 & ER- & 2 & 1,501 & 49 & $12(1 \%)$ & $17(1 \%)$ & $1056(70 \%)$ & $150(10 \%)$ \\
\hline
\end{tabular}

Table 1. Summary of characteristics of studies in the meta-analysis and effects of surgical margins on local recurrence in invasive cancer.

${ }^{*} \mathrm{P}=$ Prospective, $\mathrm{C}=$ Cohort, $\mathrm{R}=$ Retrospective; ${ }^{* \star} \mathrm{RT}=$ Radiotherapy; ${ }^{* \star} \mathrm{CT}=$ Chemotherapy 
Table 2 -Summary of results, including all subgroups. $I^{2}$ denotes heterogeneity, Egger regressions are a measure of publication bias and Duval Tweedie HRs are produced from duval and tweedie trim and fill methods

\begin{tabular}{|c|c|c|c|c|c|c|c|}
\hline & $N$ & HR & $95 \% \mathrm{Cl}$ & $p$ & $I^{2}(\%)$ & Egger $P$ & $\begin{array}{l}\text { Duval Tweedie } \\
\text { HR }\end{array}$ \\
\hline All Unadjusted & 7 & 2.88 & $2.06,4.03$ & $<0.001$ & 0 & NS & N/A \\
\hline All Adjusted & 19 & 2.64 & $2.01,3.46$ & $<0.001$ & 66 & 0.001 & $2.02(1.21-2.82)$ \\
\hline Node negative & 5 & 3.06 & $2.15,4.37$ & $<0.001$ & 0 & NS & N/A \\
\hline DCIS only & 5 & 2.91 & $1.94,4.36$ & $<0.001$ & 46 & NS & N/A \\
\hline Invasive Cancer & 12 & 2.44 & $1.78,3.34$ & $<0.001$ & 58 & NS & N/A \\
\hline Distant Recurrence & 4 & 1.53 & $1.03,2.25$ & 0.03 & 84 & NS & N/A \\
\hline No Radiotherapy & 7 & 3.52 & $2.56,4.84$ & $<0.001$ & 0 & NS & N/A \\
\hline Skin Sparing & 4 & 3.40 & $1.90,6.20$ & $<0.001$ & 0 & NS & N/A \\
\hline
\end{tabular}

Abbreviations: DCIS: Ductal carcinoma in-situ, N: Number, HR: Hazard ratio, Cl: Confidence interval 


\section{References}

1. Kennedy Review.(2013) Review of the response of Heart of England NHS Foundation Trust to concerns about Mr I Paterson's Surgical Practice: lessons to be learned and recommendations, https://hgs.uhb.nhs.uk/wp-content/uploads/Kennedy$\underline{\text { Report-Final.pdf }}$

2. Houssami N, Macaskill $P$, Marinovich ML, Morrow M. The association of surgical margins and local recurrence in women with early-stage invasive breast cancer treated with breast-conserving therapy: a meta-analysis. Ann Surg Oncol. 2014: 21(3):717-30. doi: 10.1245/s10434-014-3480-5. Epub 2014 Jan 29.

3. Rowell NP. Are mastectomy resection margins of clinical relevance? A systematic review. Breast. 2010: 19(1):14-22. doi: 10.1016/j.breast.2009.10.007.

4. Al-Himdani S, Timbrell S, Tan KT, Morris J, Bundred NJ. Prediction of margin involvement and local recurrence after skin-sparing and simple mastectomy. Eur J Surg Oncol. 2016: 42(7):935-41. doi: 10.1016/j.ejso.2016.04.055.

5. EBCTCG (Early Breast Cancer Trialists' Collaborative Group), McGale P, Taylor C, Correa C, Cutter D, Duane F et al. Effect of radiotherapy after mastectomy and axillary surgery on 10-year recurrence and 20-year breast cancer mortality: metaanalysis of individual patient data for 8135 women in 22 randomised trials. Lancet. 2014: 21;383(9935):2127-35. doi: 10.1016/S0140-6736(14)60488-8. Epub 2014 Mar 19.

6. Buchholz TA, Somerfield MR, Griggs JJ, El-Eid S, Hammond ME, Lyman GH et al. Margins for breast-conserving surgery with whole-breast irradiation in stage I and II 
invasive breast cancer: American Society of Clinical Oncology endorsement of the Society of Surgical Oncology/American Society for Radiation Oncology consensus guideline. J Clin Oncol. 2014 10;32(14):1502-6. doi: 10.1200/JCO.2014.55.1572. Epub 2014 Apr 7. Review.

7. Lanitis S, Tekkis P P, Sgourakis G, Dimopoulos N, Al Mufti R, Hadjiminas DJ, Comparison of Skin-Sparing Mastectomy Versus Non-Skin-Sparing Mastectomy for Breast Cancer A Meta-Analysis of Observational Studies. Ann Surg 2010; 251: 632 63

8. Holleczek B, Stegmaier C, Radosa JC, Solomayer EF, Brenner H. Risk of locoregional recurrence and distant metastases of patients with invasive breast cancer up to ten years after diagnosis - results from a registry-based study from Germany. BMC Cancer. 2019: 30;19(1):520. doi: 10.1186/s12885-019-5710-5.]

9. Horiguchi J, Koibuchi Y, Yoshida T, Takata D, Kikuchi M, Rokutanda N et al, Significance of local recurrence as a prognostic factor in the treatment of breast cancer Anticancer Res 2006: 26:569-574

10. Prospero systematic review, Impact of positive margins following breast surgery for breast cancer on recurrence and survival, CRD42019127541

11. Royston, P, Parmar, M. Flexible parametric proportional-hazards and proportionalodds models for censored survival data, with application to prognostic modelling and estimation of treatment effects. Stats in Medicine. 2002: 21:2175-97.

12. Collins, G, Transparent Reporting of a Multivariable Prediction Model for Individual Prognosis or Diagnosis (TRIPOD): The TRIPOD Statement, https://linkinghub.elsevier.com/retrieve/pii/S0302283814011993 
13. Zeng X, Zhang Y, Kwong JS, Zhang C, Li S, Sun F et al. The methodological quality assessment tools for preclinical and clinical studies, systematic review and metaanalysis, and clinical practice guideline: a systematic review. J Evid Based Med. 2015 Feb;8(1):2-10. doi: 10.1111/jebm.12141.

14. Higgins JPT, Li T, Deeks JJ (editors). Chapter 6: Choosing effect measures and computing estimates of effect. In: Higgins JPT, Thomas J, Chandler J, Cumpston M, Li T, Page MJ, Welch VA (editors). Cochrane Handbook for Systematic Reviews of Interventions version 6.0 (updated July 2019). Cochrane, 2019.

15. Glorioso J, Gonzalez Juarrero AB, Rodysill BR, Harmsen WS, Habermann EB, Carter JM et al. Margin. Proximity with local recurrence after mastectomy for patients not receiving adjuvant radiotherapy. Ann Surg Oncol 2017: 24:3148-3156

16. Vaughan A, Dietz JR, Aft R, Gillanders WE, Eberlein TJ, Freer P et al. Scientific Presentation Award. Patterns of local breast cancer recurrence after skin-sparing mastectomy and immediate breast reconstruction. Am J Surg. 2007: 194(4):438-43.

17. Maishman T, Cutress RI, Hernandez A, Gerty S, Copson ER, Durcan L et al. Local Recurrence and Breast Oncological Surgery in Young Women With Breast Cancer: The POSH Observational Cohort Study. Ann Surg. 2017 266(1):165-172. doi: 10.1097/SLA. 0000000000001930 .

18. Aalders KC, van Bommel AC, van Dalen T, Sonke GS, van Diest PJ, Boersma LJ et al. Contemporary risks of local and regional recurrence and contralateral breast cancer in patients treated for primary breast cancer. Eur J Cancer. 2016: 63:118-26. doi: 10.1016/j.ejca.2016.05.010. Epub 2016 Jun 11. 
19. Van der Heiden-van der Loos M, Siesling S, Wouters M, van Dalen T et al The value of ipsilateral breast tumor recurrence as a quality indicator:hospital variation in the Netherlands. Breast Cancer Res Treat 2012: 131(2):691-698.doi:10.1007/s10549011-1809-3

20. Behm EC, Beckmann KR, Dahlstrom JE, Zhang Y, Cho C, Stuart-Harris R et al. Surgical Margins and risk of locoregional recurrence in invasive breast cancer: An analysis of 10 year data from the breast cancer treatment quality assurance plan. The Breast 2013: 839-844

21. Hastings J Iganef S, Huang C, Huang R, Slezak J. Risk Factors for locoregional recurrence after mastectomy in Stage T1NO breast cancer. Am J Clin Oncol 2014: 37: $486-491$

22. Abi-Raad R, Boutrus R, Wang R, Niemierko A, Macdonald S, Smith B et al. Patterns and risk factors of locoregional recurrence in T1-T2 node negative breast cancer patients treated with mastectomy: implications for postmastectomy radiotherapy. Int J Radiat Oncol Biol Phys. 2011 Nov 1;81(3):e151-7. doi: 10.1016/j.ijrobp.2011.01.015. Epub 2011 Mar 21.

23. Ahlborn TN, Gump FE, Bodian C, Habif DV, Kister S. Tumor to fascia margin as a factor in local recurrence after modified radical mastectomy. Surg Gynecol Obstet. 1988 Jun;166(6):523-6.

24. Beriwal S, Schwartz GF, Komarnicky L, Garcia-Young JA. Breast-conserving therapy after neoadjuvant chemotherapy: long-term results. Breast J. 2006 MarApr;12(2):159-64 
25. Cataliotti L, Distante V, Ciatto S, Bianchi S, Pacini P, Simoncini R et al. Intraductal breast cancer: review of 183 consecutive cases. Eur J Cancer. 1992;28A(4-5):91720.

26. Childs SK, Chen YH, Duggan MM, Golshan M, Pochebit S, Punglia RS et al. Impact of margin status on local recurrence after mastectomy for ductal carcinoma in situ. Int J Radiat Oncol Biol Phys. 2013 Mar 15;85(4):948-52. doi: 10.1016/j.jijobp.2012.07.2377. Epub 2012 Sep 11.

27. Childs SK, Chen YH, Duggan MM, Golshan M, Pochebit S, Wong JS et al. Surgical margins and the risk of local-regional recurrence after mastectomy without radiation therapy. Int J Radiat Oncol Biol Phys. 2012 Dec 1;84(5):1133-8. doi: 10.1016/j.jirobp.2012.02.048. Epub 2012 Apr 27.

28. Choong LP, Taib NA, Rampal S, Saad M, Bustam AZ, Yip CH. High tumour stage and margin clearance are still important prognostic factors for post-mastectomy locoregional recurrence in Malaysia. Asian Pac J Cancer Prev. 2010;11(5):1409-16.

29. Fitzsullivan E, Lari SA, Smith B, Caudle AS, Krishnamurthy S, Lucci A et al. Incidence and consequence of close margins in patients with ductal carcinoma-in situ treated with mastectomy: is further therapy warranted? Ann Surg Oncol. 2013 Dec;20(13):4103-12. doi: 10.1245/s10434-013-3194-0. Epub 2013 Aug 23.

30. Freedman GM, Fowble BL, Hanlon AL, Myint MA, Hoffman JP, Sigurdson ER et al. A close or positive margin after mastectomy is not an indication for chest wall irradiation except in women aged fifty or younger. Int J Radiat Oncol Biol Phys. 1998 Jun 1;41(3):599-605. 
31. Gentilini O, Intra M, Gandini S, Peruzzotti G, Winnikow E, Luini A et al. Ipsilateral breast tumor reappearance in patients treated with conservative surgery after primary chemotherapy. The role of surgical margins on outcome. J Surg Oncol. 2006 Oct 1;94(5):375-9.

32. Goulart J, Truong P, Woods R, Speers CH, Kennecke H, Nichol A. Outcomes of node-negative breast cancer 5 centimeters and larger treated with and without postmastectomy radiotherapy. Int J Radiat Oncol Biol Phys. 2011 Jul 1;80(3):75864. doi: 10.1016/j.jijrobp.2010.02.014. Epub 2010 Jun 18.

33. Hehr T, Classen J, Huth M, Durst I, Christ G, Bamberg M, Budach W. Postmastectomy radiotherapy of the chest wall. Comparison of electron-rotation technique and common tangential photon fields. Strahlenther Onkol. 2004 Oct;180(10):629-36.

34. Huang EH, Tucker SL, Strom EA, McNeese MD, Kuerer HM, Hortobagyi GN et al. Predictors of locoregional recurrence in patients with locally advanced breast cancer treated with neoadjuvant chemotherapy, mastectomy, and radiotherapy. Int J Radiat Oncol Biol Phys. 2005 Jun 1;62(2):351-7.

35. Jagsi R, Raad RA, Goldberg S, Sullivan T, Michaelson J, Powell SN et al. Locoregional recurrence rates and prognostic factors for failure in node-negative patients treated with mastectomy: implications for postmastectomy radiation. Int J Radiat Oncol Biol Phys. 2005 Jul 15;62(4):1035-9.

36. Klein J, Kong I, Paszat L, Nofech-Mozes S, Hanna W, Thiruchelvam D et al. Close or positive resection margins are not associated with an increased risk of chest wall recurrence in women with DCIS treated by mastectomy: a population-based 
analysis. Springerplus. 2015 Jul 10;4:335. doi: 10.1186/s40064-015-1032-5. eCollection 2015.

37. Macdonald G, Paltiel C, Olivotto IA, Tyldesley S. A comparative analysis of radiotherapy use and patient outcome in males and females with breast cancer. Ann Oncol. 2005 Sep;16(9):1442-8. Epub 2005 Jun 22.

38. Meijnen P, Oldenburg HS, Peterse JL, Bartelink H, Rutgers EJ. Clinical outcome after selective treatment of patients diagnosed with ductal carcinoma in situ of the breast. Ann Surg Oncol. 2008 Jan;15(1):235-43. Epub 2007 Nov 7.

39. Merino T, Ip T, Domínguez F, Acevedo F, Medina L, Villaroel A et al. Risk factors for loco-regional recurrence in breast cancer patients: a retrospective study. Oncotarget. 2018 Jul 13;9(54):30355-30362. doi: 10.18632/oncotarget.25735. eCollection 2018 Jul 13.

40. Rashtian A, Iganej S, Amy Liu IL, Natarajan S. Close or positive margins after mastectomy for DCIS: pattern of relapse and potential indications for radiotherapy. Int J Radiat Oncol Biol Phys. 2008 Nov 15;72(4):1016-20. doi: 10.1016/j.jijrobp.2008.06.1954.

41. Rauschecker HF, Sauerbrei W, Gatzemeier W, Sauer R, Schauer A, Schmoor C et al. Eight-year results of a prospective non-randomised study on therapy of small breast cancer. The German Breast Cancer Study Group (GBSG). Eur J Cancer. 1998 Feb;34(3):315-23. 
42. Sakamoto N, Fukuma E, Teraoka K, Hoshi K. Local recurrence following treatment for breast cancer with an endoscopic nipple-sparing mastectomy. Breast Cancer. 2016 Jul;23(4):552-60. doi: 10.1007/s12282-015-0600-4. Epub 2015 Mar 17.

43. Schouten van der Velden AP, van Vugt R, Van Dijck JA, Leer JW, Wobbes T. Local recurrences after different treatment strategies for ductal carcinoma in situ of the breast: a population-based study in the East Netherlands. Int J Radiat Oncol Biol Phys. 2007 Nov 1;69(3):703-10. Epub 2007 Jun 4.

44. Timbrell S, Al-Himdani S, Shaw O, Tan K, Morris J, Bundred N. Comparison of Local Recurrence After Simple and Skin-Sparing Mastectomy Performed in Patients with Ductal Carcinoma In Situ. Ann Surg Oncol. 2017 Apr;24(4):1071-1076. doi: 10.1245/s10434-016-5673-6. Epub 2016 Nov 11.

45. Truong PT, Olivotto IA, Speers CH, Wai ES, Berthelet E, Kader HA. A positive margin is not always an indication for radiotherapy after mastectomy in early breast cancer. Int J Radiat Oncol Biol Phys. 2004 Mar 1;58(3):797-804.

46. Truong PT, Sadek BT, Lesperance MF, Alexander CS, Shenouda M, Raad RA et al. Is biological subtype prognostic of locoregional recurrence risk in women with pT12NO breast cancer treated with mastectomy? Int J Radiat Oncol Biol Phys. 2014 Jan 1;88(1):57-64. doi: 10.1016/j.jrobp.2013.09.024. Epub 2013 Oct 22.

47. Wadasadawala T, Kannan S, Gudi S, Rishi A, Budrukkar A, Parmar V et al. Predicting loco-regional recurrence risk in T1, T2 breast cancer with 1-3 positive axillary nodes postmastectomy: Development of a predictive nomogram. Indian J Cancer. 2017 Jan-Mar;54(1):352-357. doi: 10.4103/ijc.IJC_178_17. 
48. Woodward WA, Strom EA, Tucker SL, Katz A, McNeese MD, Perkins GH et al. Locoregional recurrence after doxorubicin-based chemotherapy and postmastectomy: Implications for breast cancer patients with early-stage disease and predictors for recurrence after postmastectomy radiation. Int J Radiat Oncol Biol Phys. 2003 Oct 1;57(2):336-44.

49. M. L Marinovich, L Azizi, P Macaskill, L Irwig, M Morrow, L J Solin, and N Houssami The Association of Surgical Margins and Local Recurrence in Women with Ductal Carcinoma In Situ Treated with Breast Conserving Therapy: A MetaAnalysis Ann Surg Oncol . 2016 November ; 23(12): 3811-3821. doi:10.1245/s10434-016-5446-2.

50 Morrow M ,Van Zee KJ,Solin L, Houssami N,Chavez-MacGregor M, Harris J, Horton J et Al Society of Surgical Oncology-ASTRO-ASCO Consensus guideline on margins for Breast Conserving Surgery with whole breast irradiation in DCIS. Ann Surg Oncol 2016:23:3801-3810

50. National Institute for Health and Clinical Excellence. NG101 Early and locally advanced breast cancer - diagnosis and treatment. 2018. National Collaborating Centre for Cancer, Recommendations 1.3, Published July 2018, https://www.nice.org.uk/guidance/ng101/chapter/Recommendations\#surgery-tothe-breast 
51 Mannu GS, Wang Z,Broggio J,Charman J, Cheung S, Kearins O,Dodwell D, Darby SC. Invasive breast cancer and breast cancer mortality after DCIS in women attending for breast screening in England 1988-2014.BMJ2020:369:m1570

52 Mallon PT, McIntosh SA. Post mastectomy radiotherapy in breast cancer: a survey of current United Kingdom practice.J BUON. 2012 Apr-Jun;17(2):245-8.PMID:22740200

\section{Contributors}

JR Bundred performed the meta-analysis, was involved in writing the manuscript, providing the figures and organising the NOS review.

S Michael, S Bowers, N Barnes and Y Jauhari were involved in reviewing the papers, writing and reviewing the manuscript.

D Plant was involved with performing the NOS review and reviewing the manuscript.

R Cutress and Tom Maishman provided data from POSH study on mastectomy patients, and reviewed the manuscript.

B Holleczek provided data and reviewed the manuscript.

D Dodwell was involved with the original concept of a systematic review, reviewing the data and writing the manuscript.

NJ Bundred conceived the systematic review, organised the paper review and search, performed NOS review, wrote the manuscript, reviewed the data and is responsible for the findings. 